\title{
Dialects on Screen: Translating Jordanian Dialect into English The Case of Captain Abu Raed Film
}

\author{
Hamza Ethelb \\ Faculty of Languages, University of Tripoli \\ Libya
}

\begin{abstract}
This article explores the translation of dialects on-screen within the Jordanian context. Such place of translation is arguably one of the most challenging areas of translation, yet interesting due to its variety. Arab peoples use their dialects to express their opinions on several platforms, including TV media. Audiovisual translation research is growing in investigating subtitling Arabic dialects and languages on screen. Scholars propose a dialect-to-dialect approach or a dialect-to-standard approach. However, in this paper the focus is more on the strategies which inevitably fall within those approaches. The study uses a Jordanian film known as Captain Abu Raed as a source of highlighting and demonstrating translation of dialects within an Arabic context. The initial findings show that some dialectal expressions are taken off or sacrificed by replacing them with neutralized standard language.
\end{abstract}

Keywords: Arabic, dialects, film, screen translation, subtitling

Cites as: Ethelb, H. (2019). Dialects on Screen: Translating Jordanian Dialect into English The Case of Captain Abu Raed Film. Arab World English Journal for Translation \& Literary Studies3 (4) 36-45. DOI: http://dx.doi.org/10.24093/awejtls/vol3no4. 